\title{
Malondialdehyde and Pentosidine in Young Type 1 Diabetic Patients
}

\author{
Soha M. Abd El Dayem¹, Ehsan A. Badawy El Sheikh², Sadek Saied Abdou², Mervat Harvi Agaibyi², Marwa Mahmoud² \\ ${ }^{1}$ Pediatrics Department, National Research Centre, Medical Physiology, El Tahrir St., Dokki Cairo, Cairo 12622, Egypt; ${ }^{2}$ Medical \\ Biochemistry Department, Chemistry, Cairo, Egypt
}

\begin{abstract}
Citation: El Dayem SMD, El Sheikh EAB, Abdou SS, Agaibyi MH, Mahmoud M. Malondialdehyde and Pentosidine in Young Type 1 Diabetic Patients. Maced J Med Sci. 2012 Dec 15; 5(4):428-433. http://dx doi org/10.3889/MJMS.1957http://dx.doi.org/1

Key words: Malondialdehyde; Pentosidine; type 1 diabetic patient.

Correspondence: Soha M. Abd El Dayem, Professor of Pediatrics. National Research Centre, Cairo, Egypt. E-mail: S_eldayem@Yahoo.com

Received: 15-Jan-2012; Revised: 01-Apr-2012; Accepted: 11-Apr-2012; Online first: 19-Nov-2012

Copyright: (c) 2012 El Dayem SMD. This is an open-access article distributed under the terms of the Creative Commons Attribution License, which permits unrestricted use, distribution, and reproduction in any medium, provided the original author and source are credited.

Competing Interests: The author have declared
\end{abstract} that no competing interests exist.

\section{Abstract}

Objective: To investigate whether advanced glycosylation end products (AGE) and oxidative stress are augmented in young patients with type 1 diabetes at early clinical stages of the disease.

Patients and Methods: The study included 50 patients with type 1 diabetes among those attending the endocrine clinic in National Research Centre and 30 healthy volunteers in the control group. Serum glucose, total cholesterol, low-density lipoprotein cholesterol (LDL-c), high-density lipoprotein cholesterol (HDL-c), triglycerides, serum creatinine concentrations, glycosylated hemoglobin (HbA1c), urinary albumin/ creatinine ratio, malondialdehyde and pentosidine were assessed.

Results: No significant difference was found between age of patients $(12.0 \pm 3.2)$ and controls $(11.0$ $\pm 1.2), P>0.05$. Blood glucose, HbA1c, urinary albumin / creatinine ratio, pentosidine and malondialdehyde were significantly higher in diabetic patients than controls. Pentosidine and malondialdehyde had a significant positive correlation with blood glucose, $\mathrm{HbA1c}$ and urinary albumin/creatinine ratio.

Conclusion: The present study indicates that accumulation of AGEs, whose formation is closely linked to oxidative stress, and resultant endothelial dysfunction may start early in the course of type 1 diabetes. This means that the risk of vascular complications may be present at an early age and that the best possible glycemic control should be emphasized from the diagnosis of diabetes.

\section{Introduction}

Glucose and reducing sugars react non enzymatically with protein amino groups to form reversible Schiff base adducts, which, upon molecular rearrangement, convert in vivo into the more stable Amadori products such as glycosylated hemoglobin $(\mathrm{HbA1c})$. A small proportion of Amadori products are then irreversibly transformed, over several weeks to months, into advanced glycosylation end products (AGEs). The latter process is slow and affects mainly proteins with a slow turnover, such as matrix tissue proteins [1].
Generation of AGEs was first described as an epiphenomenon of aging. AGE contents slowly increase with age in a variety of collagenous structures, such as vascular wall collagen and basement membranes. Subsequent studies showed accumulation of AGEs during the progression of diabetes, where as others identified AGEs in the blood and tissues of patients with chronic renal failure [2].

There is increasing evidence that AGEs play a pivotal role in atherosclerosis, in particular in diabetes. AGE accumulation is notjust a measure of hyperglycemia, 
but represents cumulative metabolic burden (both hyperglycemia and hyperlipidemia), oxidative stress and inflammation [3]. Interaction between AGEs and AGE specific receptors induce inflammatory reactions and endothelial dysfunction [4].

AGE level (especially carboxy methyl lysine) is a strong predictor for the development and progression of microvascular complications including nephropathy [5]. AGEs have a predictive value for the development of microvascular complications, which was found to be superior to other common risk predictors, such as diabetes duration and $\mathrm{HbA} 1 \mathrm{c}[6]$.

It has been hypothesized that AGEs play a causal role in the development of a variety of diabetic complications. AGEs accumulate in plasma and tissue proteins of patients with diabetes. Their accumulation correlates with the severity of diabetic complications. Miyata and colleagues recently demonstrated that carboxy methyl-lysine (CML) and pentosidine, which are AGE compounds, accumulate in expanded mesangial matrix and nodular lesions in diabetic nephropathy, in co-localization with lipid peroxidation end products such as malondialdehyde - lysine, 4-hydroxy nonenal-protein adduct, and acrolein- protein adduct $[1,2]$. Some AGEs like pentosidine have intrinsic fluorescence, and as such, tissue and plasma fluorescence can be used as markers of AGE accumulation. Other AGEs such as CML are non fluorescent and may be detected by approaches such as ELISA [7].

We are aiming to investigate whether advanced glycated end product production and oxidative stress are augmented in young patients with type 1 diabetes at early clinical stages of the disease.

\section{Patients and Methods}

This cross sectional observational prospective study was performed after obtaining approval by the ethical committee of the National Research Centre. Written informed consent was obtained from all patients and their parents and also controls after full discussion about the aim of the study.

The study included 50 patients with type 1 diabetes (19 males and 31 females) among those attending the endocrine clinic in National Research Centre. All patients had prepubertal onset of diabetes, had undergone diabetes education, and were being treated with intensified insulin therapy (two doses of intermediate acting insulin and premeal injection of rapid acting insulin according to blood glucose monitoring with reagent strips). At the time of the study, they were free from any clinical or biological signs of acute infection, and no patients had ketone bodies in their urine. There was no evidence of retinopathy (as determined by fundoscopy) or peripheral neuropathy (as determined by evaluating peripheral nervous conduction velocity). A control group of 30 children and adolescents (14 males and 16 females) with no family history of diabetes who came to the outpatient pediatric clinic for minor problems, such as recurrent abdominal pain, dyspepsia, or recurrent otitis, were also enrolled.

\section{Assessment of blood pressure}

Blood pressure was measured three times after 5 -minute rest in the sitting position on both upper limbs with the use of automatic manometer (Omron M4 Plus, Omron Healthcare Europe, Hoofddorp, Holland). The mean value of the second and the third measurement was calculated.

\section{Laboratory methods}

All subjects were submitted to the following laboratory investigations:

Sample collection after a 12-h overnight fast, blood specimens were obtained to determine serum glucose, total cholesterol, low-density lipoprotein cholesterol (LDL-c), high-density lipoprotein cholesterol (HDL-c), triglycerides, serum creatinine concentrations, and $\mathrm{HbA1C}$. In addition, another sample was collected in tubes containing ethylene diamine tetra acetate (EDTA) or heparin and was centrifuged at 3,000 $\mathrm{g}$ for $5 \mathrm{~min}$ at $4^{\circ} \mathrm{C}$. The plasma and serum were separated, and aliquots were stored at " $80^{\circ} \mathrm{C}$ until analyses of malondialdehyde (MDA) and pentosidine were performed.

1 - Concentration of serum cholesterol, HDL-c, LDL-C and triglycerides were measured using the commercially available enzymatic in vitro tests by Roche (Cholesterol CHODPAP, HDL-C Plus, LDL-C Plus, Triglycerides GPO-PAP; Hitachi, Roche Diagnostics).

2 - Determination of fasting blood glucose: This was carried out by the enzymatic colormetric method of Tinder [8].

3 - Determination of glycosylated hemoglobin (HbA1c): Glycosylated hemoglobin measured using ion exchange resin and colorimetric determination by Stanbio Laboratory (USA) [9]. 
4-Determination of urinary albumin: The method measured the shift in the absorption spectrum from 460 to $600 \mathrm{~nm}$ of the complex that occurred at acid pH between pyrogallol red-molibdate (PRM) and the basic amino groups of urine and cerebro spinal fluid (CSF) proteins. The intensity of the colored complex formed was proportional to the concentration of protein in the sample [10].

5 - Determination of urinary creatinine: The color intensity was directly proportional to the creatinine concentration in the sample. It was determined by measuring the increase in absorbance at $546 \mathrm{~nm}[11]$.

6 - Determination of Plasma MDA: The plasma underwent alkaline hydrolysis, acid deproteinization, derivatization with TBA (thiobarbituric acide) and nbutanol extraction. After this, MDA was determined at $532 \mathrm{~nm}$ by high performance liquid chromatographic (HPLC) [12].

7 - Determination of plasma pentosidine: Reverse-phase HPLC was used for the determination of the plasma pentosidine content.Briefly, $50 \mu$ of plasma were lyophilized and then hydrolyzed by $50 \mu$ of $6 \mathrm{~N} \mathrm{HCl}$ at $110^{\circ} \mathrm{C}$ under nitrogen atmosphere for $16 \mathrm{~h}$, subsequently neutralized with $100 \mu \mathrm{l}$ of $5 \mathrm{~N} \mathrm{NaOH}$ and $200 \mu \mathrm{l}$ of $0.5 \mathrm{M}$ phosphate buffer $(\mathrm{pH} 7.4)$, and then filtered through a $0.45-\mu \mathrm{m}$ Millipore filter and diluted 20 fold with phosphate-buffered saline (PBS). Filtered samples $(50 \mu \mathrm{l})$ were then injected into $\mathrm{C} 18$ reversephase analytical column (218TP104, Vydac; Separation Group, Hesperia, CA) using online fluorescence detector at excitation/emission wavelengths of 335/385 nm [13].

\section{Statistical analysis}

Statistical Package for Social Sciences (SPSS) program version 10.0 was used for analysis of data. Data was expressed as means $\pm S D$, median and range. Data was tested for normal distribution using one-sample Kolomongorov- Simirnov test for total sample and subgroups, which revealed that data was not normally distributed. Non parametric Test (Mann-Whitney U test) was used for analysis of 2 quantitative data. Correlations between malondialdehyde and pentosidine and other variables were evaluated by Spearman's test. Partial correlations between Pentosidine and malondialdehyde versus urinary albumin/creatinine ratio was done after adjusting for blood glucose and HbA1c levels. Values of $p<0.05$ were taken as statistically significant.

\section{Results}

The study included 50 children with type 1 diabetes, their mean age were $12.0 \pm 3.2 \mathrm{yrs}$ ( $8.0-19.5$ $\mathrm{yrs})$ and mean duration of diabetes was $5.5 \pm 3.4 \mathrm{yrs}(0.2$ $-11.8 \mathrm{yrs}$ ). Their mean total cholesterol level was 159.0 $\pm 36.6(110.0-222.0)$, mean triglyceride level was 84.9 $\pm 58.3(37.0-217.0)$, mean HDL-c was $53.5 \pm 17.6$ (33.6 - 83.0) and mean LDL-c was $94.0 \pm 28.7$ (57.0 - 125.0). No significant difference was found between age of patients $(12.0 \pm 3.2)$ and controls $(11.0 \pm 1.2), P>0.05$. Blood glucose, $\mathrm{HbA} 1 \mathrm{c}$, urinary albumin / creatinine ratio, pentosidine and malondialdehyde were significantly higher in diabetic patients than controls (Table 1).

Table 1: Comparison between demographic and laboratory data of diabetic patients and controls.

\begin{tabular}{|c|c|c|c|}
\hline Variables & $\begin{array}{c}\text { Patients Median Mean } \pm \\
\text { SD (Range) } N=50\end{array}$ & $\begin{array}{c}\text { Controls Median } \\
\text { Mean } \pm \mathrm{SD} \\
\text { (Range) } \mathrm{N}=30\end{array}$ & $P$ - value \\
\hline Age (yrs) & $\begin{array}{c}10.8 \\
12.0 \pm 3.2 \\
(8.0-19.5)\end{array}$ & $\begin{array}{c}10.0 \\
11.0 \pm 1.2 \\
9.0-19.0)\end{array}$ & 0.1 \\
\hline $\begin{array}{l}\text { Systolic blood pressure } \\
(\mathrm{mmHg})\end{array}$ & $\begin{array}{c}110 \\
109.7 \pm 10.3 \\
(90.0-130.0)\end{array}$ & $\begin{array}{c}110 \\
104.5 \pm 10.6 \\
(80.0-120.0)\end{array}$ & 0.08 \\
\hline $\begin{array}{l}\text { Diastolic blood pressure } \\
\text { (mmHg) }\end{array}$ & $\begin{array}{c}70 \\
71.9 \pm 10.1 \\
(60.0-95.0) \\
0.8\end{array}$ & $\begin{array}{c}65 \\
67.7 \pm 9.2 \\
(50.0-80.0) \\
0.4\end{array}$ & 0.1 \\
\hline Pentosidine(pmolar) & $\begin{array}{c}1.1 \pm 0.5 \\
(0.7-2.3) \\
1.1\end{array}$ & $\begin{array}{c}0.4 \pm 0.08 \\
(0.3-0.5) \\
0.6\end{array}$ & 0.0001 \\
\hline Malondialdehyde( $\mu$ molar) & $\begin{array}{c}1.3 \pm 0.4 \\
(0.9-2.1) \\
166.5\end{array}$ & $\begin{array}{c}0.6 \pm 0.03 \\
(0.5-0.7) \\
160.0\end{array}$ & 0.0001 \\
\hline Total cholesterol (mg/dl) & $\begin{array}{c}159.0 \pm 26.6 \\
(110.0-222) \\
73\end{array}$ & $\begin{array}{c}160.0 \pm 30.0 \\
(100.0-190.0) \\
70\end{array}$ & 0.1 \\
\hline Triglyceride (mg/dl) & $\begin{array}{c}84.8 \pm 58.3 \\
(37.0-217.0) \\
50.0\end{array}$ & $\begin{array}{c}80.0 \pm 30.0 \\
(30.0-150.0) \\
49.0\end{array}$ & 0.2 \\
\hline HDL-c (mg/dl) & $\begin{array}{c}53.5 \pm 17.6 \\
(33.6-83.0) \\
97.0\end{array}$ & $\begin{array}{c}49.0 \pm 15.0 \\
(35.0-90.0) \\
95\end{array}$ & 0.2 \\
\hline $\mathrm{LDL}-\mathrm{c}(\mathrm{mg} / \mathrm{dl})$ & $\begin{array}{c}94.0 \pm 28.7 \\
(57.0-125.0)\end{array}$ & $\begin{array}{c}90.0 \pm 20.0 \\
(50.0-110.0)\end{array}$ & 0.3 \\
\hline $\begin{array}{l}\text { Fasting blood glucose } \\
(\mathrm{mg} / \mathrm{dl})\end{array}$ & $\begin{array}{c}220 \\
226.8 \pm 54.5 \\
(150.0-330.0)\end{array}$ & $\begin{array}{c}91 \\
91.5 \pm 10.6 \\
(65.0-105.0)\end{array}$ & 0.0001 \\
\hline $\begin{array}{l}\text { Glycosylated hemoglobin } \\
(\%)\end{array}$ & $\begin{array}{c}8.8 \\
8.9 \pm 1.5 \\
(6.7-11.7)\end{array}$ & $\begin{array}{c}5.1 \\
5.2 \pm 0.4 \\
(4.6-6.4)\end{array}$ & 0.0001 \\
\hline $\begin{array}{l}\text { Albumin/creatinine ratio } \\
\text { ( } \mu \mathrm{g} / \mathrm{gm} \text { creatinine })\end{array}$ & $\begin{array}{c}39.8 \\
47.6 \pm 18.8 \\
(27.3-100.0)\end{array}$ & $\begin{array}{c}13.6 \\
12.9 \pm 1.9 \\
(8.8-16.6)\end{array}$ & 0.0001 \\
\hline
\end{tabular}

Non Parametric (Mann Whitney $-U$ ) test was used

No significant difference was found in pentosidine and malondialdehyde in relation to sex $(P>0.05)$. Urinary albumin / creatinine ratio had no significant correlation with serum cholesterol, triglyceride and LDL-C. Pentosidine and malondialdehyde had a significant positive correlation with blood glucose, $\mathrm{HbA} 1 \mathrm{c}$ and urinary albumin / creatinine ratio. On the other hand pentosidine and malondialdehyde had no significant correlation with systolic and diastolic blood pressure and lipid profile (Table 2). Correlations between Pentosidine and malondialdehyde versus urinary albumin/creatinine ratio showed no significant difference after adjusting for blood 
Table 2: Correlation between pentosidine and malondialdehyde with demographic and laboratory data of diabetic patients.

\begin{tabular}{|c|c|c|c|c|}
\hline \multirow{2}{*}{ Variables } & \multicolumn{2}{|c|}{ Pentosidine } & \multicolumn{2}{|c|}{ Malondialdehyde } \\
\hline & rs & $P$-value & is & $P$-value \\
\hline Age (yrs) & -0.1 & 0.5 & -0.1 & 0.7 \\
\hline Duration of diabetes (yrs) & -0.2 & 0.2 & -0.2 & 0.2 \\
\hline $\begin{array}{l}\text { Systolic blood pressure } \\
(\mathrm{mmHg})\end{array}$ & -0.1 & 0.5 & -0.2 & 0.4 \\
\hline $\begin{array}{l}\text { Diastolic blood pressure } \\
(\mathrm{mmHg})\end{array}$ & -0.2 & 0.4 & -0.2 & 0.2 \\
\hline Pentosidine (pmolar) & --- & --- & 0.9 & 0.0001 \\
\hline Malondialdehyde ( $\mu$ molar) & 0.9 & 0.0001 & --- & ---- \\
\hline Total cholesterol (mg/dl) & -0.001 & 0.9 & -0.1 & 0.8 \\
\hline Triglyceride $(\mathrm{mg} / \mathrm{dl})$ & 0.4 & 0.3 & 0.5 & 0.1 \\
\hline $\mathrm{HDL}-\mathrm{c}(\mathrm{mg} / \mathrm{dl})$ & -0.1 & 0.7 & -0.1 & 0.8 \\
\hline $\mathrm{LDL}-\mathrm{c}(\mathrm{mg} / \mathrm{dl})$ & -0.7 & 0.3 & -0.7 & 0.3 \\
\hline $\begin{array}{l}\text { Fasting blood glucose } \\
\text { (mg/dl) }\end{array}$ & 0.9 & 0.0001 & 0.9 & 0.0001 \\
\hline $\begin{array}{l}\text { Glycosylated hemoglobin } \\
(\%)\end{array}$ & 0.8 & 0.0001 & 0.9 & 0.0001 \\
\hline $\begin{array}{l}\text { Albumin/creatinine ratio } \\
\text { ( } \mu \mathrm{g} / \mathrm{gm} \text { creatinine })\end{array}$ & 0.7 & 0.0001 & 0.7 & 0.0001 \\
\hline
\end{tabular}

Spearman's correlation was used

glucose and HbA1c levels. No correlation was found between Pentosidine and malondialdehyde and other parameters in control subjects.

\section{Discussion}

In our study, blood glucose, HbA1c, urinary albumin / creatinine ratio, pentosidine and MDA were significantly higher in diabetic patients. Firoozrai et al., [14], reported that diabetic patients had higher oxidative stress in both children and adolescents, with respect to the control group, as demonstrated by the increase in MDA. MDA is produced by break down of lipids under oxidative stress conditions. Evidence of lipid peroxidation has been reported to be present in a number of diabetic complications [15], and it is significantly contributes to endothelial dysfunction which is a key event in the pathogenesis of diabetic microvascular disease. Their finding is consistent with previous reports of higher MDA levels in erythrocytes and plasma of type 1 diabetic patients $[14,15]$.

In the present study, urinary albumin / creatinine ratio had no significant correlation with serum cholesterol, triglyceride and LDL-C.

Development of microvascular disease in diabetes is enhanced by dyslipidemia. Serum lipids have been associated with progression of nephropathy at each stage of renal disease [16]. In adolescents, hypercholesterolemia remained a significant predictor of subsequent persistent MDA, with LDL-c being more important for its initiation [17]. Mesangial cells express receptors for oxidized $L D L$, which upon activation induce mesangial cell proliferation and increase mesangial matrix deposition.

In the current study, as systolic and diastolic blood pressure and lipid profile showed no significant difference between patients and controls. pentosidine and MDA had no significant correlation with systolic and diastolic blood pressure and lipid profile.

AGEs accumulate within various organs that are damaged in diabetes, with the accumulation rate of these AGEs accelerated by hyperglycemia. The intermolecular collagen cross-linking caused by AGEs leads to diminished arterial and myocardial compliance and increased vascular stiffness, phenomena that are considered to explain partly the increase in diastolic dysfunction and systolic hypertension seen in diabetic subjects [18]. AGEs accumulate in most sites of diabetes complications, including the kidney, retina, and atherosclerotic plaques. AGEs have been measured and reported to be linked to the sustained effects of prior glycemic control on the subsequent development of vascular complications.

In our study, Pentosidine and MDA had a significant positive correlation with blood glucose, HbA1c and urinary albumin / creatinine ratio. Correlations between Pentosidine and malondialdehyde versus urinary albumin/creatinine ratio showed no significant difference after adjusting for blood glucose and HbA1c levels.

In diabetes, AGE accumulation may result from chronic hyperglycemia promoting generation of AGEs, and also with concomitant impaired renal function because the kidney is the major site of AGE clearance. AGE modified proteins may be more resistant to enzymatic degradation [7], and it is likely that this further promotes local tissue AGE accumulation.

Chiarelli et al. [19], found a close correlation between serum AGE concentrations and the severity of diabetic retinopathy and microalbuminuria. A highly significant relationship between glycemic control (based on $\mathrm{HbA1c}$ ) and collagen-linked AGEs was also demonstrated in skin biopsy specimens from adults with type 1 diabetes [20].

Hyperglycemia not only generates reactive oxygen species but also attenuates antioxidant mechanisms, causing consumption of antioxidants such as á-tocopherol and intracellular glutathione[21].

The long-term complications of diabetes mellitus are the leading causes of morbidity and mortality in the 
diabetic population. In recent reports, increased oxidative stress has been suggested to be a contributory factor in the pathogenesis and development of diabetic complications [22]. Activation of multiple metabolic pathways in diabetes leads to increased generation of reactive oxygen species. However, oxidative effects of reactive oxygen species are generally controlled by both endogenous and exogenous antioxidants [23].

Oxidative stress increases progressively during the course of the disease and is correlated with glycemic control [24]. The pathophysiology of diabetic nephropathy (DN) is complex. Poor glycemic control is well recognized as a contributing factor. Glucose induced oxidative stress exists in mesangial cells cultured in high glucose conditions, as evidenced by elevated MDA and decreased glutathione levels (GSH) [25].

Long-term glycemic control appears to be the most important factor influencing the development of nephropathy. Diabetes causes abnormalities in endothelium dependent regulation of vasomotor tone and increases glomerular blood flow and permeability [26], which initiates and maintains the early glomerular hyperfiltration. A unifying hypothesis that combines several important pathogenic pathways implicated in glucose-mediated vascular damage could be the mitochondrial superoxide production theory [27]. High levels of free radicals could lead to destruction of major components of cellular structure and affect various cell functions. Recently, in an animal model (streptozotocintreated rats), it was shown that morphological changes in DN improved after antioxidant treatment [28], suggesting that kidney damage could be mediated by oxidation. Thus, the imbalance in the oxidant/antioxidant status system that accompanies diabetes could be considered an important pathogenic mediator of diabetic microvascular injury.

\section{Limitation of the study}

1-The cost of assay of pentosidine high.

2-The number of diabetic patients was small and we need to do it in a large scale.

We conclude that accumulation of AGEs, whose formation is closely linked to oxidative stress, and resultant endothelial dysfunction may start early in the course of type 1 diabetes. This means that the risk of vascular complications may be present at an early age and that the best possible glycemic control should be emphasized from the diagnosis of diabetes.
As the oxidative stress to proteins and lipid peroxidation could begin to damage the renal glomerulus during the first few years of diabetes, this is the ideal time to initiate interventions and encourage not only a strict glycemic and lipid control but also a diet with sufficient intake of foods rich in antioxidants to counteract the oxidant effects that contribute to the diabetes complication mechanisms.

\section{References}

1. Tsukahara H, Sekine K, Uchiyama M, Kawakami H, Hata I, Todoroki Y, Hiraoka M, Kaji M, Yorifuji T, Momoi T, Yoshihara K, Beppu M, Mayumi M. Formation of Advanced Glycosylation End Products and Oxidative Stress in Young Patients with Type 1 Diabetes. Pediatric Research. 2003;54:419-24.

2. Miyata T, Kurokawa K, van Ypersele de Strihou C. Advanced glycation and lipoxidation end products: role of reactive carbonyl compounds generated during carbohydrate and lipid metabolism. J Am Soc Nephrol. 2000;11:1744-52.

3. Baynes JW, Thorpe SR. Glycoxidation and lipoxidation in atherogenesis. Free Radic Biol Med. 2000;28:1708-16.

4. Meerwaldt R, Links T, Zeebregts C, Tio R, Hillebrands J, Smit $A$. The clinical relevance of assessing advanced glycation end products accumulation in diabetes. Cardiovasclar Diabetology. 2008;7(29):1 - 8.

5. Genuth S, Sun W, Cleary P, Sell DR, Dahms W, Malone J, Sivitz W, Monnier VM. Glycation and carboxymethyl lysine levels in skin collagen predict the risk of future 10-year progression of diabetic retinopathy and nephropathy in the diabetes control and complications trial and epidemiology of diabetes interventions and complications participants with type 1 diabetes. Diabetes. 2005:54:3103-11.

6. Gerrits EG, Lutgers HL, Kleefstra N, Graaff R, Groenier KH, Smit AJ, Gans RO, Bilo HJ. Skin Autofluorescence: A Tool to Identify Type 2 Diabetic Patients at Risk for Developing Microvascular Complications. Diabetes Care. 2007;26:1755 -60 .

7. Goh S, Cooper ME. The Role of Advanced Glycation End Products in Progression and Complications of Diabetes. J Clin Endocrinol Metab. 2008;93:1143-52.

8. Trinder P. Determination of Glucose in Blood Using Glucose Oxidase with an Alternative Oxygen Acceptor. Ann Clin Biochem. 1969;6:24-5.

9. Niederau CM, Reinauer H. Comparison of analytical methods for the estimation of glycosylated haemoglobins. J Clin Chem Clin Biochem. 1981;19(11):1097-101.

10. Orsonneau JL, Douet P, Massoubre C, Lustenberger P, Bernard S. An improved pyrogallol red-molybdate method for 
determining total urinary protein. Clinical Chemistry. 1989;35: 2233-36.

11. Grotto D, Santa Maria LD, Boeira S, Valentini J, Charão MF, Moro AM, Nascimento PC, Pomblum VJ, Garcia SC. Rapid quantification of malondialdehyde in plasma by high performance liquid chromatography-visible detection. Journal of Pharma Biomed Anal. 2007;43(2):619-24.

12. Kroll MH, Chesler R, Hagengruber C, Blank DW, Kestner $\mathrm{J}$, Rawe M.. Automated determination of urinary creatinine without sample dilution: theory and practice. Clinical Chemistry. 1986;32:446-52.

13. Odetti P, Fogarty J, Sell DR, Monnier VM. Chromatographic quantitation of plasma and erythrocyte pentosidine in diabetic and uremic subjects. Diabetes. 1992; 41(2):153-59.

14. Firoozrai M, Nourbakhsh M, Razzaghy-Azar M. Erythrocyte susceptibility to oxidative stress and antioxidant status in patients with type 1 diabetes. Diabetes Res Clin Pract. 2007; $77: 427-32$

15. Martin-Gallán $P$, Carrascosa $A$, Gussinyé $M$, Domí nguez C. Biomarkers of diabetes-associated oxidative stress and antioxidant status in young diabetic patients with or without subclinical complications. Free Radic Biol Med. 2003; 34:156374.

16. Thomas $M C$, Rosengard-Bärlund $M$, Mills $V$, Rönnback M,Thomas S, Forsblom C, Cooper ME, Taskinen MR, Viberti G, Groop PH . Serum lipids and the progression of type 1 diabetes. Diabetes Care. 2006;29:317-22.

17. Stone ML, Craig ME, Chan AK, Lee JW, Verge CF, Donaghue KC. Natural history and risk factors for microalbuminuria in adolescents with type 1 diabetes: a longitudinal study. Diabetes Care. 2006;29:2072-77.

18. Cooper ME, Bonnet F, Oldfield M, Jandeleit-Dahm K. Mechanisms of diabetic vasculopathy: an overview. Am J Hypertens. 2001;14:475-86.

19. Yan SF, Ramasamy R, Bucciarelli LG, Wendt T, Lee LK,
Hudson BI, Stern DM, Lalla E, DU Yan S, Rong LL, Naka Y, Schmidt AM. RAGE and its ligands: a lasting memory in diabetic complications? Diab Vasc Dis Res. 2004;1:10-20.

20. Humpert PM, Kopf S, Djuric Z, Wendt T, Morcos M, Nawroth PP, Bierhaus A. Plasma sRAGE is independently associated with urinary albumin excretion in type 2 diabetes. Diabetes Care. 2006;29:1111-13.

21. Martin-Gallán P, Carrascosa A, Gussinyé M, Domí nguez C. Estimation of lipoperoxidative damage and antioxidant status indiabetic children: relationship with individual antioxidants. Free Radic Res. 2005;39:933-42.

22. Martin-Gallán P, Carrascosa A, Gussinyé M, Domí nguez C. Oxidative stress in childhood type 1 diabetes: Results from a study covering the first 20 years of evolution. Free Radic Res. 2007;41:919-28.

23. Hernández-Marco R, Codoñer-Franch $P$, Morales SP, Villaescusa CD, Garcí a LB, Bellés VV. Oxidant/antioxidant status and hyperfiltration in young patients with type 1 diabetes mellitus. Pediatric Nephrol. 2009;24:121-27.

24. Firoozrai M, Nourbakhsh M, Razzaghy-Azar M. Erythrocyte susceptibility to oxidative stress and antioxidant status in patients with type 1 diabetes. Diabetes Res Clin Pract. 2007; 77:427-32.

25. Catherwood MA, Powell LA, Anderson P, McMaster D, Sharpe PC, Trimble ER. Glucose-induced oxidative stress in mesangial cells. Kidney Int. 2002;61:599-608.

26. Levine DZ. Can rodent models of diabetic kidney disease clarify the significance of early hyperfiltration?: recognizing clinical and experimental uncertainties. Clin Sci. 2008; 114:109-18.

27. Brownlee M. Biochemistry and molecular cell biology of diabetic complications. Nature. 2001;414:813-20.

28. Taghizadeh Afshari A, Shirpoor A, Farshid A, Saadatian R, RasmiY, Saboory E, Ilkhanizadeh B, Allameh A. The effect of ginger on diabetic nephropathy, plasma antioxidant capacity and lipid peroxidation in rats. Food Chem. 2007;101:148-53. 